\title{
A competitividade das exportações do Brasil e da China para o Mercosul: evidências para o período 1995-2009
}

\author{
Palavras-chave \\ comércio internacional, \\ similaridade \\ das exportações, \\ competitividade

\section{Classificação JEL} \\ F14

\section{Keywords} \\ international trade, export \\ similarity, competitiveness
}

\section{JEL Classification \\ F14}

*Universidade Estadual de Ponta Grossa

**Universidade Federal do Paraná

***Universidade Estadual de

Ponta Grossa

\author{
Alex Sander Souza do Carmo* \\ Maurício Vaz Lobo Bittencourt** \\ Augusta Pelinski Raiher ${ }^{* * *}$
}

\section{Resumo}

O objetivo central do presente trabalho é analisar a competitividade das exportações do Brasil e da China para o Mercosul no período compreendido entre 1995 e 2009. Para tanto, calcula-se o índice de similaridade das exportações do Brasil e da China para esse bloco econômico, e, em seguida, desagrega-se esse índice, conforme o critério de similaridade dos produtos. Os principais resultados mostraram que a similaridade das exportações do Brasil e da China para o Mercosul vem aumentando ao longo do tempo. No entanto, quando se desagregou o índice de Finger e Kreinin (1979), verificou-se que a similaridade das exportações ocorre, majoritariamente, em produtos verticalmente diferenciados, em que a qualidade do produto exportado pelo Brasil é superior à qualidade do produto exportado pela China. Os resultados sugerem que a competição entre o Brasil e a China no Mercosul tem sido suavizada, tendo em vista que os produtos exportados pelos países são direcionados para distintos segmentos de mercado.

\section{Abstract}

The main goal of this paper is to investigate the competitiveness of Brazilian and Chinese exports to MERCOSUL for the period from 1995 to 2009. In order to do this, the Finger and Kreinin (1979) export similarity index (ESI) is calculated for the Brazilian and Chinese exports to MERCOSUL, which is disaggregated according to the similarities of the goods. The main results showed that the similarity between Brazilian and Chinese exports to MERCOSUL has increased over time, possibly due to an increase in the competition between these countries. However, when disaggregated from the Finger and Kreinin (1979) index, it is shown that the similarities between the exports occur, mainly, with vertically differentiated goods, where the quality of the goods exported by Brazil was superior to that of the goods exported by China. The results suggest that the competition between Brazil and China in the MERCOSUL is smooth, since the goods exported by these countries aim at different market segments. 


\section{1_Introdução}

No decorrer das últimas décadas, o crescimento econômico chinês é algo sem precedentes na história econômica recente. Uma considerável parte desse crescimento se deve ao desempenho do comércio internacional (Rodrick, 2006). A título de ilustração, a participação do comércio internacional no PIB chinês passou de $0 \%$, durante os anos sessentas, para, aproximadamente, 30\% em 2006 (Rodrick, 2006). Como resultado dessa elevação, em 2008, a China já despontava no cenário internacional como o terceiro maior exportador, permanecendo atrás apenas dos Estados Unidos e da Alemanha.

O processo de inserção internacional da China vem chamando a atenção da literatura econômica, tendo em vista que recentemente esse país se tornou a segunda maior economia mundial. Rodrick (2006) destaca que, apesar de os setores intensivos em trabalho ainda possuírem papel importante nas exportações, a China vem intensificando as suas exportações em produtos mais sofisticados, fazendo do país um paradoxo para a teoria econômica, uma vez que, não obstante possuir renda per capita baixa, consegue ter uma pauta de exportação altamente sofisticada e diversificada, semelhante à de países com renda per capita três vezes mais elevada. Nesse caso, Rodrick (2006) destaca que, se o país tivesse uma estrutura de exportação em conformidade com o seu nível de renda, as suas taxas de crescimento econômico seriam substancialmente menores.

Ressalta-se que o aumento da participação chinesa na economia internacional tem impacto direto sobre o comércio exterior brasileiro. No período entre 2000 e 2009, a corrente de comércio (exportação + importação) entre o Brasil e a China passou de US\$2,3 bilhões para US $\$ 56,4$ bilhões (IPEA, 2011), fazendo desse país o principal parceiro comercial do Brasil em 2009. Destaca-se também que o padrão de comércio dos países apresenta clara natureza interindustrial, em que o Brasil exporta basicamente commodities (minério de ferro, soja e derivados, produtos de couro, celulose) e importa majoritariamente produtos industrializados (equipamentos elétricos, produtos químicos inorgânicos, instrumentos óticos, material fotográfico) (IPEA, 2011).

Um ponto importante a salientar é que a inserção internacional da China pode comprometer o comércio internacional brasileiro, já que, se por um lado esse país constitui-se um importante mercado de destino para as exportações brasileiras, por outro, os produtos chineses podem concorrer com os produtos brasileiros em outros mercados, caso a estrutura de exportação dos países se tornar mais similar ao longo do tempo.

Nesse campo de pesquisa, Filgueiras e Kume (2010) analisam o grau de similaridade das estruturas de exportação do Brasil e da China no mercado norte-americano. Por meio da aplicação do índice de Finger e Kreinin (1979), ${ }^{1}$ os autores verificaram que a similaridade das exportações desses países para o mercado norte-americano aumentou de 0,11 para 0,15, entre os anos 2000 e 2005, mas voltou a reduzir após este ano, atingindo, em 2008, o valor de 0,10. Os autores sugerem que o decréscimo nessa magnitude pode estar relacionado a um possível deslocamento das exportações brasileiras ocasionado pelo aumento das exportações chinesas para os Estados Unidos.

Para Fontagné et al. (2007), a competição entre os países no comércio internacional pode ser atenuada, caso os produtos por eles exportados sejam verticalmente diferenciados, ou, em outras palavras, possuam distintas qualidades, visto que, nessa circunstância, se acredita que os produtos exportados pelos países são comercializados em distintos segmentos de mercado.

Dessa forma, Fontagné et al. (2007) avaliam a competição entre a União Europeia e a China em produtos vertical- 
mente diferenciados, onde esses foram agrupados em três categorias - baixa, média e alta qualidade -, considerando o valor unitário do produto. Entre outros resultados, os autores concluem que, no período entre 1995 e 2004, a União Europeia concentrou as suas exportações no segmento de alta qualidade, ao passo que as exportações chinesas são concentradas no segmento de baixa qualidade. Em consequência disso, os resultados obtidos nesse trabalho sugerem que a competição entre as exportações tem sido suavizada, tendo em vista que os produtos exportados não se destinam ao mesmo segmento de mercado.

Partindo dos trabalhos de Filgueiras e Kume (2010) e de Fontagné et al. (2007), o objetivo central do presente trabalho é analisar a competitividade das exportações do Brasil e da China para o Mercosul, ${ }^{2}$ no período compreendido entre 1995 e 2009. Para tanto, mensura-se o índice de similaridade das exportações de Finger e Kreinin (1979) e, em seguida, desagrega-se tal índice com base no critério de similaridade dos produtos; nesse caso, será possível avaliar se a qualidade dos produtos brasileiros é superior ou inferior à qualidade dos produtos chineses.

A importância deste trabalho está relacionada ao fato de que será possível identificar o grau de similaridade das exportações do Brasil e da China para o Mercosul e, adicionalmente, será possível compreender de forma mais detalhada como ocorre a competição entre esses países no referido mercado. Ademais, o presente trabalho inova ao propor uma desagregação do índice de Finger e Kreinin (1979), com base no critério de similaridade dos produtos.

Além da presente introdução, este artigo possui outras quatro seções. Na seção 2, apresenta-se o referencial teórico. Na sequência (seção 3), descrevem-se a estratégia empírica e a fonte de dados. Na seção 4, reporta-se a análise dos resultados. Por fim, na seção 5, têm-se as considerações finais.

\section{2_Revisão da literatura}

\section{1_Conceitos iniciais: diferenciação horizontal e vertical dos produtos}

Os produtos comercializados pelas firmas são diferenciados conforme as suas características ou atributos, em que essa diferenciação pode ocorrer de forma horizontal ou vertical.

De acordo com Church e Ware (2000, p. 369), entende-se por diferenciação horizontal quando os consumidores possuem preferências heterogêneas sobre o produto, não existindo consenso entre esses sobre qual produto é o melhor, tendo em vista que as diferenças entre os produtos ofertados são muito sutis. Por outro lado, no caso da diferenciação vertical, os produtos possuem diferenças substanciais entre si no quesito qualidade, fazendo com que exista relativo consenso entre os consumidores sobre qual produto é o melhor.

Para melhor distinguir os conceitos de diferenciação horizontal e vertical, descreve-se o seguinte exemplo didático, em relação à indústria automobilística: na economia, comumente os consumidores se deparam com o lançamento de carros populares, sendo esses, em geral, produzidos por firmas distintas. Nesse caso, esses automóveis podem ser descritos como produtos diferenciados, uma vez que possuem algumas características e atributos que os distinguem uns dos outros, mas essas diferenças são pontuais e pequenas, fazendo com que não exista consenso entre os consumidores sobre qual carro popular é o melhor.

Em relação à diferenciação vertical, os produtos apresentam diferenças substanciais no que tange às suas qualidades. As diferenças entre as qualidades ficam evidentes quando os carros populares são comparados aos carros de luxo. Nesse caso, os carros de luxo possuem uma série de características e atributos que os deixam em um patamar muito superior aos carros populares, tornando possível aos consumidores apontarem que os carros de luxo são melhores do que os carros populares. 


\section{2_Modelos teóricos de diferenciação}

horizontal e vertical dos produtos

A teoria neoclássica de comércio internacional teve os seus fundamentos básicos formulados no modelo de Hecksher-Ohlin (doravante H-O). Nesse modelo, o comércio internacional é determinado pelas vantagens comparativas dos países, que, por sua vez, são oriundas da abundância relativa dos fatores de produção, capital e trabalho. O principal resultado desse modelo afirma que os países capital-abundantes devem se especializar na produção/exportação de produtos capital-intensivos, ao passo que os países trabalho-abundantes devem se especializar na produção/exportação de produtos trabalho intensivo. A resultante disso será um padrão de comércio essencialmente interindustrial, no qual os produtos trocados pelos países serão de distintas indústrias.

Os pressupostos básicos do modelo H-O começaram a ser questionados na literatura quando Balassa (1966) e Grubel (1967) verificaram que o comércio internacional entre os países pertencentes à recém-formada Comunidade Econômica Europeia ocorria em duas vias, isto é, a pauta de exportação dos países era similar, e, em consequência disso, o padrão de comércio internacional apresentava uma natureza intraindustrial.

Não obstante as evidências empíricas terem iniciado nos anos sessentas, apenas no final dos anos setentas é que emergiu na literatura os modelos teóricos de comércio intraindústria, em que se destacam os seminais trabalhos de Krugman (1979, 1980, 1981).

Krugman (1981), partindo de uma estrutura de mercado que opera em concorrência monopolística, economias de escala sendo internas às firmas e de que a preferência do consumidor é do tipo "amor por variedade" ("love of variety"), mostra que a pauta de exportação dos países será mais similar, e o padrão de comércio possui natureza intraindústria. Mais do que isso, esse modelo aponta que a especialização produtiva dos países não ocorre mais ao nível de indústria, como no modelo $\mathrm{H}-\mathrm{O}$, mas sim, ao nível de produto, em que esse é diferenciado de forma horizontal (em variedade).

Aprofundando o modelo de Krugman (1981), Helpman e Krugman (1985) compatibilizam em um mesmo arcabouço teórico os padrões de comércio interindustrial e intraindustrial. Nesse modelo, assume-se que o comércio interindustrial é explicado com base nas vantagens comparativas dos países, como no modelo H-O, enquanto o padrão intraindustrial é explanado, valendo-se de uma estrutura de mercado que opera em concorrência monopolística, de que as economias de escala são internas às firmas e de que a preferência do consumidor é do tipo "love of variety", assim como em Krugman (1981). O resultado final do modelo de Helpman e Krugman (1985) mostra que a pauta de exportação dos países será mais similar quanto maior for a similaridade nas relações capital-trabalho dos países, e o contrário ocorrerá quanto mais os países se diferenciarem em termos da razão capital-trabalho.

Vale aqui frisar que os modelos de Krugman (1979, 1980, 1981) e de Helpman e Krugman (1985) partem da premissa de que a especialização produtiva dos países pode ocorrer ao nível de produto, em que esse é diferenciado de forma horizontal, ou seja, em variedade. No entanto, identificam-se também na literatura teórica modelos que consideram que a especialização intraproduto pode ocorrer de forma vertical, quando esse é diferenciado em qualidade, como em Falvey (1981), Falvey e Kierzkowski (1987), Flam e Helpman (1987) e Grossman e Helpman (1991).

Falvey (1981) e Falvey e Kierzkowski (1987) demonstraram que a diferenciação vertical dos produtos é consequência direta das diferenças nas funções de produção dos par- 
ceiros comerciais. Nessa situação, o país capital-abundante especializar-se-á na produção de produtos diferenciados de alta qualidade, ao passo que o país trabalho-abundante especializar-se-á na produção de produtos de baixa qualidade. Assim, os modelos de Falvey (1981) e Falvey e Kierzkowski (1987) podem ser vistos como um resgate do modelo $\mathrm{H}-\mathrm{O}$, mas com a diferença de que, enquanto no modelo H-O a especialização da produção ocorre ao nível de indústria, nos modelos de Falvey (1981) e Falvey e Kierzkowski (1987) a especialização ocorre ao nível de produto, ou seja, as variedades de um produto possuem diferentes qualidades.

Assim, enquanto o modelo de H-O prevê o comércio de diferentes bens, o modelo baseado em Falvey (1981) e Falvey e Kierzkowski (1987) considera o comércio de diferentes variedades de um bem, mas com distintas qualidades. De acordo com Greenaway e Milner (1986), os modelos do tipo "Falvey" podem ser vistos como modelos neo-Heckscher-Ohlin de comércio intraindústria. Estes se baseiam nos pressupostos descritos em Jones (1974) e Deardorff (1979), em que: (i) todos os países têm acesso à mesma tecnologia de produção; (ii) a tecnologia disponível é do tipo retornos constantes à escala; (iii) os países, pelo lado da oferta, diferem apenas na dotação relativa de fatores; (iv) diferentes variedades de um bem têm diferentes requerimentos de fatores de produção, ou seja, quanto maior for a qualidade, maior será a intensidade relativa de capital; e (v) os preços dos fatores são apenas parcialmente equalizados. ${ }^{3}$

Tem-se ainda o modelo de Flam e Helpman (1987), o qual considera que as diferenças entre as qualidades dos produtos são procedentes das diversidades tecnológicas entre os países. Nesse caso, os países tecnologicamente mais avançados especializar-se-ão na exportação do produtos de maior qualidade, enquanto aqueles tecnologicamente menos avançados especializar-se-ão nos produtos de menor qualidade.
Na mesma linha de Flam e Helpman (1987), Grossman e Helpman (1991) desenvolvem um modelo teórico do ciclo do produto, conhecido na literatura como "quality ladder model". Nesse modelo, os países tecnologicamente mais avançados utilizam as suas vantagens comparativas em inovação para desenvolver novos produtos, com qualidade superior a dos produtos existentes no mercado. Posteriormente, após adentrarem no mercado, esses novos produtos passam, então, a ser copiados pelos países seguidores.

\section{3_Diferenciação horizontal e vertical:}

o que diz a literatura empírica?

Com o desenvolvimento de bases de dados de comércio internacional em níveis mais desagregados, vêm emergindo na literatura empírica diversos estudos que objetivam analisar tanto a similaridade das pautas de exportações dos países quanto a especialização intraproduto.

Hummels e Klenow (2005), por exemplo, utilizando uma base de dados composta de 126 países exportadores e 59 países importadores, e com os fluxos comerciais desagregados a seis dígitos do Sistema Harmonizado para o ano de 1995, encontram evidências robustas de que os países com maiores níveis de renda per capita exportam um número maior de produtos, penetram os seus produtos em um número maior de mercados, e os preços dos produtos exportados são ligeiramente mais elevados, em que se assume que o preço do produto reflete a sua qualidade. Dessa forma, os autores concluem que existe no comércio internacional uma especialização produtiva ao nível de produto, em que as nações mais desenvolvidas se especializam na produção e na exportação dos produtos de maior qualidade, ao passo que as nações menos desenvolvidas se especializam na produção e na exportação dos produtos de menor qualidade. 
Nessa mesma linha, Schott (2006), utilizando dados das importações dos Estados Unidos, desagregados ao nível de 10 dígitos do Sistema Harmonizado, observa que os Estados Unidos importam o mesmo produto de vários países, mas o preço desses produtos varia sistematicamente conforme o nível de renda dos parceiros comerciais. Nesse caso, as evidências mostram que os preços dos produtos oriundos dos países mais ricos são mais elevados do que os preços dos produtos procedentes dos países mais pobres; dessa maneira, assume-se que o maior preço do produto revela a sua maior qualidade. Schott (2006) advoga que as firmas oriundas dos países capital-abundantes utilizam as suas vantagens na produtividade para se especializarem na produção de produtos de maior qualidade e mitigar a competição com os produtos de baixa qualidade, oriundos dos países trabalho-abundante.

Seguindo essa lógica, Fontagné et al. (2007) afirmam que a competição entre os países pode ser atenuada se os produtos por eles exportados forem diferenciados em qualidade. Objetivando analisar a competição entre a União Europeia e a China no mercado internacional, com base no valor unitário dos produtos, os autores dividem os fluxos comerciais em baixa, média e alta qualidade e procuraram identificar em qual segmento os países se inserem. Nesse caso, os autores observaram que as exportações da União Europeia estão concentradas no segmento de alta qualidade, ao passo que a China apresentou elevada participação no segmento de baixa qualidade. ${ }^{4}$ Com isso, os autores concluem que a competição entre a União Europeia e a China no mercado internacional é mitigada em razão da forma de diferenciação dos produtos.

Os resultados obtidos em Faruq (2010) mostram que a qualidade dos produtos exportados está diretamente relacionada com as atividades de pesquisa e desenvolvimento, corroborando a hipótese dos modelos de liderança tecnológica
(Flam; Helpman, 1987; Grossman; Helpman, 1991). Ademais, Faruq (2010) também encontra evidências de que a qualidade dos produtos é determinada pelo Investimento Direto Externo, confirmando os resultados de Reganati e Pittiglio (2005) e Caetano e Gallego (2007). Nesse caso, acredita-se que, quando realiza um investimento, uma firma estrangeira leva consigo uma nova tecnologia, que acaba aperfeiçoando a qualidade dos produtos exportados pelo país hospedeiro.

Krishna e Maloney (2011) analisam a pauta de importação dos Estados Unidos, no período compreendido entre 1990-2001, e utilizam como proxy da qualidade dos produtos os seus valores unitários. Os autores identificaram que os Estados Unidos importam o mesmo produto de vários países, mas esses produtos possuem grandes diferenças em seus valores unitários (interpretadas como diferenças nas qualidades), onde esses, por sua vez, são positivamente correlacionados com o nível de renda per capita dos países. Com isso, os autores advogam que existe especialização intraproduto no comércio internacional contemporâneo, corroborando os resultados encontrados em Hummels e Klenow (2005) e Schott (2006). Ademais, Krishna e Maloney (2011) identificam ainda que a taxa de crescimento da qualidade dos produtos vem aumentando ao longo do tempo, mas de forma diferenciada entre os países, onde as maiores taxas são observadas para os países mais ricos, pertencentes à OCDE.

Kang e Lee (2012) analisam a qualidade relativa dos produtos comercializados entre a Coreia do Sul e 15 países da OCDE, mais Taiwan, no período compreendido entre 1996-2003. Para tanto, os autores desagregaram os fluxos comerciais bilaterais em alta qualidade e baixa qualidade. Primeiramente, observou-se que a qualidade dos produtos exportados pela Coreia do Sul é inferior à qualidade dos produtos exportados pela OCDE. Em seguida, os autores objetivam identificar quais são os principais determinantes dos produtos de alta 
qualidade. Por meio da metodologia de dados em painel, os autores verificaram que as diferenças na disponibilidade de capital físico tendem a aumentar o comércio de produtos verticalmente diferenciados, corroborando a hipótese central dos modelos de Falvey (1981) e Falvey e Kierzkowski (1987).

\section{3_Metodologia}

Os estudos descritos na seção anterior evidenciam que a especialização produtiva dos países ocorre na forma intraproduto, em que esses podem ser diferenciados de forma horizontal ou vertical. Quando esses são diferenciados de forma vertical, a competição entre os países no mercado internacional é atenuada, tendo em vista que os produtos destinam para diferentes segmentos de mercado. Seguindo essa ideia, na presente seção, descreve-se a metodologia para identificar como vem ocorrendo a competição entre o Brasil e a China no mercado do Mercosul, ou seja, se essa ocorre em produtos diferenciados em variedade ou em qualidade, de acordo com os pressupostos dos modelos teóricos de Falvey (1981) e Falvey e Kierzkowski (1987).

Para tanto, a metodologia a ser utilizada no presente trabalho será definida em duas partes. Na primeira, por meio do índice de Finger e Kreinin (1979), identificam-se quais são os produtos simultaneamente exportados pelo Brasil e pela China para o Mercosul. Posteriormente, observa-se como ocorre a diferenciação desses produtos, ou seja, se eles são diferenciados de forma horizontal ou vertical.

\section{1_Mensuração e decomposição do índice de similaridade das exportações}

No presente artigo, a mensuração da similaridade das exportações do Brasil e da China para o Mercosul será realizada por meio do índice de Finger e Kreinin (1979), o qual pode ser representado como:

$$
\mathrm{ISE}_{\mathrm{ijmt}}=\sum_{\mathrm{k}=1}^{\mathrm{n}} \min \left(\mathrm{C}_{\mathrm{kimt}} ; \mathrm{C}_{\mathrm{kjmt}}\right)
$$

Onde: $I S E_{i j m t}$ denota o índice de similaridade das exportações do país $i$ (Brasil) e do país $j$ (China), no mercado $m$ (Mercosul), no tempo t; $C_{k i m t}$ é a participação do produto $k$, na pauta de exportação do país $i$ (Brasil), no mercado $m$ (Mercosul), no tempo t; $C_{k j m t}$ é a participação do produto $k$, na pauta de exportação do país $j$ (China), no mercado $m$ (Mercosul), no tempo t.

Destaca-se que o índice de similaridade das exportações (ISE) varia no intervalo compreendido entre o e 1 . Nesse caso, quando as exportações do país $i$ (Brasil) e do país $j$ (China) apresentarem a mesma distribuição, o índice será igual a 1; por outro lado, quando as exportações dos países apresentarem distribuições completamente distintas, o índice será igual a 0 . Assim, um índice ISE próximo da unidade pode ser um indício de que a competição entre o Brasil e a China no Mercosul é bastante acirrada.

Mas, neste trabalho, propõe-se uma forma de decompor o índice de Finger e Kreinin (1979), com a qual será possível identificar se a similaridade das exportações do Brasil e da China para o Mercosul ocorre em produtos horizontal ou verticalmente diferenciados. Essa decomposição será feita com base no critério de similaridade dos produtos (Crespo; Fontoura, 2004), que define a forma de diferenciação deles a partir da divisão do valor unitário do produto $k$ exportado pelo Brasil $\left(V U_{k t}^{B}\right)$ e pela China $\left(V U_{k t}^{C}\right)$ para o Mercosul. ${ }^{5}$

Nesse caso, assume-se que, caso a razão obtida a partir da divisão dos valores unitários ${ }^{6}\left[\lambda=V U_{k t}^{B} / V U_{k t}^{C}\right]$ fique próxima à unidade, se considera que os produtos comercializados pelos países não possuem diferenças significativas entre si, em consequência disso, os mesmos são definidos 
como diferenciados horizontalmente; em caso contrário, quando a razão entre os valores unitários afasta-se demasiadamente da unidade, julga-se que os produtos comercializados pelos países possuem diferenças significativas entre si, isto é, os mesmos são diferenciados verticalmente. Cabe ainda salientar que o critério utilizado para definir se $\lambda$ está próximo ou afastado da unidade será baseado no intervalo de dispersão definido por: $[(1-\alpha) ;(1+\alpha)]$. Assim, quando $\lambda$ pertencer a esse intervalo, considera-se que os produtos comercializados são diferenciados horizontalmente, caso contrário, eles serão diferenciados verticalmente.

Destaca-se que, nas situações em que os produtos exportados pelos países forem considerados como diferenciados verticalmente, o critério de similaridade permite ainda identificar se a qualidade dos produtos exportados pelo Brasil é superior ou inferior à qualidade dos produtos exportados pela China. Nesse caso, considerando o ponto de vista do Brasil, a qualidade será considerada inferior ou superior quando $\lambda<$ $(1-\alpha)$ ou $\lambda>(1+\alpha)$, respectivamente. A Figura 1 ilustra a diferenciação dos produtos conforme o critério de similaridade.

Um ponto de extrema importância a destacar, no tocante à aplicação do critério de similaridade do produto, refere-se à definição do parâmetro $\alpha$, uma vez que esse tem a propriedade de definir a forma com que os produtos comercializados pelos países são diferenciados. Seguindo
Greenaway et al. (1994), Durkin e Krygier (2000), Nielsen e Lüthje (2002), Crespo e Fontoura (2004) e Jensen e Lüthje (2009), utilizar-se-á no presente trabalho um fator de dispersão (a) igual a 25\%. ${ }^{7}$ Assim, o intervalo para a identificação da diferenciação horizontal do produto será definido por $[0,75 ; 1,25]$; caso a razão entre os valores unitários $(\lambda)$ fique fora desse intervalo, os produtos serão considerados como diferenciados verticalmente.

Outro ponto importante a ressaltar é que o critério de similaridade parte do pressuposto de que o valor unitário do produto serve de proxy para a sua qualidade. Conforme Greenaway et al. (1994), a lógica para a utilização do valor unitário como proxy da qualidade deriva-se da pressuposição de que os consumidores possuem informação perfeita e são capazes de distinguir a qualidade dos produtos ofertados no mercado, em que o bem de maior qualidade terá um valor unitário superior ao do bem de pior qualidade. Já para Stiglitz (1987), o valor unitário (preço) terá relação positiva com a qualidade do produto até mesmo quando os consumidores não possuírem informação perfeita. ${ }^{8}$

E importante enfatizar que todos os estudos sobre a qualidade dos produtos na área de comércio internacional partem do pressuposto de que, a um alto nível de desagregação, preços relativos refletem qualidade relativa, conforme Greenaway et al. (1994).

Figura 1_A diferenciação do produto conforme o critério de similaridade

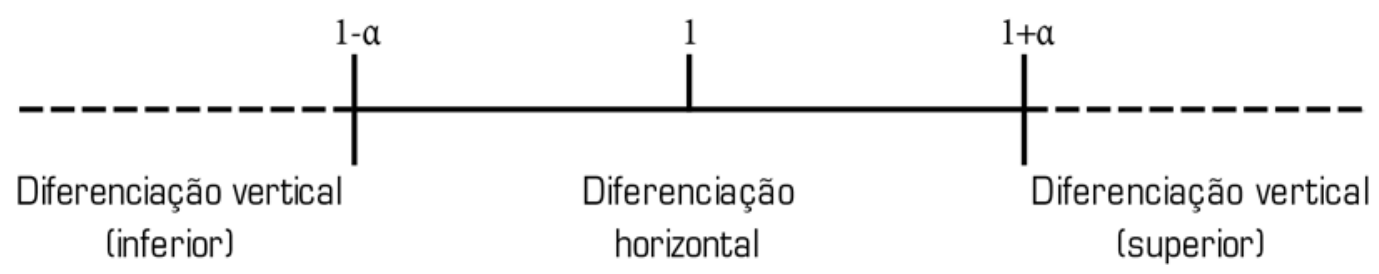

Fonte: Elaborado pelos autores. 
Fontagné et al. (1997) reconhecem que a associação direta entre o valor unitário e a qualidade apresenta algumas limitações, visto que outros fatores, como, por exemplo, as estruturas de mercado, as diferenças de custos, as diferenças de tecnologia, podem afetar o valor unitário do produto e, com isso, levar a uma interpretação errônea sobre a qualidade dele. Já Fontagné et al. (2007) apontam que a adoção do valor unitário como proxy da qualidade utiliza a hipótese restritiva de que a produtividade dos países é homogênea, seguindo os pressupostos descritos em Jones (1974) e Deardorff (1979).

Não obstante essas limitações, Fontagné et al. (2007) advogam que, do ponto de vista empírico, a qualidade que diferencia os produtos exportados estão presentes nos valores unitários, tornando-se plausível assumir que o valor unitário do produto seja uma proxy da sua qualidade.

Após a aplicação do critério de similaridade do produto,o índice de similaridade das exportações (ISE), que fora descrito na equação (1), pode ser decomposto da seguinte forma:

$$
\mathrm{ISE}_{\mathrm{ijmt}}=\mathrm{ISE}_{\mathrm{ijmt}}^{\mathrm{H}}+\mathrm{ISE}_{\mathrm{ijmt}}^{\mathrm{V}}
$$

Ou, ainda:

$$
\mathrm{ISE}_{\mathrm{ijmt}}=\mathrm{ISE}_{\mathrm{ijmt}}^{\mathrm{H}}+\mathrm{ISE}_{\mathrm{ijmt}}^{\mathrm{V}-\mathrm{Inf}}+\mathrm{ISE}_{\mathrm{ijmt}}^{\mathrm{V}-\mathrm{Sup}}
$$

Desse modo, o índice de similaridade das exportações (ISE) entre os países $i$ (Brasil) e $j$ (China), no mercado $m$ (Mercosul), no tempo $t$, será o somatório do índice de similaridade das exportações em produtos diferenciados horizontalmente $\left(I S E_{i j m t}^{H}\right)$ e do índice de similaridade das exportações em produtos diferenciados verticalmente $\left(I S E_{i j m t}^{V}\right)$, no qual este último pode ainda ser decomposto em vertical inferior $\left(I S E_{i j m t}^{V-I n f}\right)$ e vertical superior $\left(I S E_{i j m t}^{V-S u p}\right)$. O Quadro 1 sumariza tal interpretação doíndice de similaridade das exportações.
Quadro 1_Índice de similaridade das exportações e

\begin{tabular}{|c|c|}
\hline Índice & Forma de interpretação \\
\hline ISE & $\begin{array}{l}\text { Mensura a similaridade das estruturas de } \\
\text { exportações dos países i e j no mercado m, mas } \\
\text { não identifica se os produtos são diferenciados } \\
\text { horizontal ou verticalmente. }\end{array}$ \\
\hline ISE $^{H}$ & $\begin{array}{l}\text { Refere-se à parte da similaridade das } \\
\text { exportações que ocorre em produtos } \\
\text { diferenciados horizontalmente. }\end{array}$ \\
\hline ISEV $^{\mathrm{V}}$ & $\begin{array}{l}\text { Denota a parte da similaridade das exporta- } \\
\text { ções que ocorre em produtos diferenciados } \\
\text { verticalmente. }\end{array}$ \\
\hline ISE ${ }^{V-I n f}$ & $\begin{array}{l}\text { Neste caso, quando a similaridade das exportações } \\
\text { ocorre em produtos diferenciados verticalmente, a } \\
\text { qualidade do produto oriundo do país i (Brasil) é inferior } \\
\text { à qualidade do produto oriundo do país j (China). }\end{array}$ \\
\hline ISEV-Sup. & $\begin{array}{l}\text { Nesta situação, quando a similaridade das } \\
\text { exportações ocorre em produtos diferenciados } \\
\text { verticalmente, a qualidade do produto oriundo do } \\
\text { país } i \text { (Brasil) é superior à qualidade do produto } \\
\text { oriundo do país j (China). }\end{array}$ \\
\hline
\end{tabular}
as formas de interpretação

Fonte: Elaborado pelos autores.

\section{2_Fonte dos dados}

Cabe aqui destacar que o índice de Finger e Kreinin (1979), descrito na subseção anterior, é sensível ao nível de desagregação dos dados de comércio, em que esse tende a ser mais elevado quanto maior for o nível de agregação utilizado. Dessa forma, para atingir os objetivos propostos no presente artigo, utilizar-se-ão os dados de comércio desagregados ao nível de seis dígitos do Sistema Harmonizado, o que inclui mais de 5.000 produtos. ${ }^{9}$ Esses dados são oriundos da Base pour l'Analyse du Commerce International (BACI), publicada pelo Centre d'Etudes Prospectives et d'Informations Internationales (CEPII) e disponível para download no sítio: http://www.cepii.fr/anglaisgraph/bdd/baci.htm. Enfati- 
za-se que esses dados se referem ao período compreendido entre 1995 e 2009.

A utilização da base de dados da BACI possui vantagem em relação às outras bases de dados de comércio internacional, como a do COMTRADE, por exemplo. Enquanto a maioria das bases de dados reportam as exportações em valores FOB (Free on Board) e as importações em valores CIF (Cost, Insurance and Freight), na BACI, os valores monetários das exportações e das importações são compatíveis em uma base FOB-FOB, tendo em vista que os custos CIF foram estimados e retirados dos valores das importações. Para mais detalhes da base BACI, ver Gaulier e Zignago (2010).

É importante reconhecer que a utilização dos dados de comércio ao nível de seis dígitos, apesar de esses serem extremamente desagregados, possui, pelo menos, um problema potencial. Baldwin (2006) refere-se ao fato de que esses dados não mensuram o número total de produtos individuais exportados pelos países, tendo em vista que um grande número de produtos deve estar compreendido sob uma mesma categoria do Sistema Harmonizado. Sendo assim, entende-se que os valores obtidos no presente artigo tendem a superestimar o verdadeiro grau de similaridade das exportações do Brasil e da China para o Mercosul. Mas, apesar dessa limitação, acredita-se que os dados utilizados neste trabalho podem fornecer um bom panorama acerca da inserção comercial do Brasil e da China no Mercosul.

\section{4_Análise dos resultados}

\section{1_Evolução das exportações do Brasil e da China para o Mercosul, no período de 1995 a 2009}

Antes de analisar a competitividade das exportações do Brasil e da China para o Mercosul, convém realizar um breve relato acerca das evoluções das exportações desses países
Figura 2_Evolução das exportações do Brasil e da China para o Mercosul, período 1995 a 2009

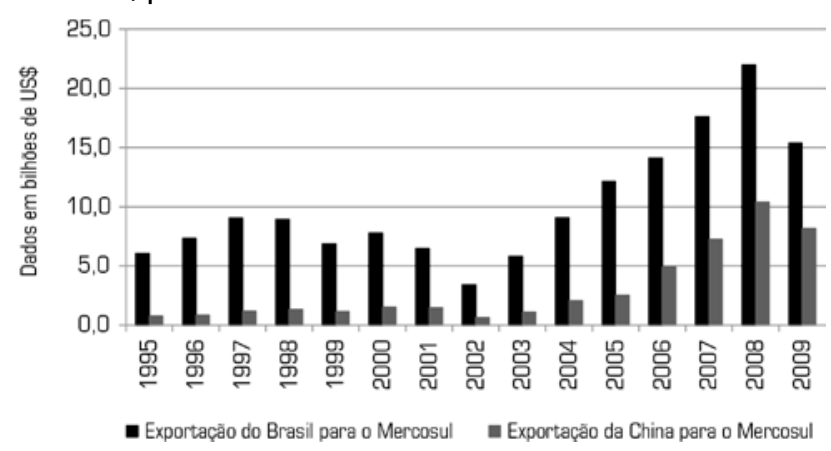

Fonte: Cômputo dos autores com os dados fornecidos pela BACI.

Nota: Os valores das exportações estão a preços correntes.

para o referido mercado, no período compreendido entre 1995 e 2009, como reportado na Figura 2. Pode-se observar nessa figura que as exportações do Brasil para o Mercosul, ao longo de todo o período, são superiores às da China, mas a diferença entre elas vem ficando cada vez menor ao longo do tempo. Por exemplo, em 1995, as exportações da China para o Mercosul representavam apenas 12,2\% (US\$ 0,74 bilhões/US\$ 6,03 bilhões) das exportações brasileiras para esse mercado, mas, em 2009, esse valor ultrapassou 53,0\% (US\$ 8,14 bilhões/US\$ 15,35 bilhões), evidenciando o aumento da participação dos produtos chineses no Mercosul. ${ }^{10}$

Os dados reportados na Tabela 1 fornecem a composição setorial das exportações do Brasil e da China para o Mercosul, destacando que os valores apresentados estão em porcentagens médias para os subperíodos de 1995/1997 e 2007/2009. No caso do Brasil, tanto para o período 1995/1997 quanto para o período 2007/2009, as exportações concentraram-se, principalmente, nos setores Transporte, Máquina/Elétrico e Químico, os quais, em conjunto, representaram em torno de $51,3 \%$ e $58,7 \%$ das exportações brasileiras para o Mercosul nos referidos períodos, respectivamente. Isso evidencia 
que as exportações do Brasil para esse bloco econômico ficaram um pouco mais concentradas ao longo do tempo, e que essa concentração está associada sobretudo pelo incremento das exportações do setor de Transporte, que aumentou a sua participação de $21,3 \%$ para $26,9 \%$, entre os períodos de 1995/1997 e 2007/2009.

Ainda com relação aos dados da Tabela 1, observa-se que, no período 1995/1997, as exportações da China para o Mercosul concentraram-se, principalmente, nos setores Máquinas/Elétrico, Produtos Diversos e Têxtil, representando, conjuntamente, em torno de 63,3\% das exportações desse país para o Mercosul. Já no período 2007/2009, as exportações concentraram-se nos seguintes setores: Máquinas/Elétrico, Químico e Produtos Diversos, em que esses de forma conjunta representaram $73,5 \%$ das exportações da China para o Mercosul. Com efeito, da mesma forma que foi verificado para o Brasil, também ocorreu aumento da concentração das exportações da China para o Mercosul, e esse aumento foi ocasionado principalmente pelo incremento das exportações do setor de Máquinas/Elétrico, que aumentou a sua participação de 31,3\% para 51,0\% entre os períodos de 1995/1997 e 2007/2009.

Os dados reunidos na Tabela 2 descrevem a evolução das exportações do Brasil e da China para o Mercosul em número de produtos (categorias a seis dígitos do Sistema Harmonizado). Nesta tabela, observa-se que, entre 1995 e 2002, o número de produtos exportados pelo Brasil para o referido bloco entrou em uma trajetória descendente, reduzindo de 3.668 para 3.251. Após leve recuperação entre os anos 2003 a 2005, quando passou de 3.330 para 3.491, o número total de produtos exportados pelo Brasil entrou em nova trajetória descendente no período entre 2006 e 2009, quando passou de 3.406 para 3.253 .

No caso da China, verifica-se que o número total de produtos exportados por esse país para o Mercosul, entre $1995 \mathrm{e}$
Tabela 1_Composição setorial das exportações do Brasil e da China para o Mercosul (porcentagem média para os subperíodos 1995/1997 e 2007/2009)

\begin{tabular}{|c|c|c|c|c|}
\hline \multirow{2}{*}{ Setor } & \multicolumn{2}{|l|}{ Brasil } & \multicolumn{2}{|l|}{ China } \\
\hline & $1995 / 1997$ & $2007 / 2009$ & $1995 / 1997$ & $2007 / 2009$ \\
\hline $\begin{array}{l}\text { Animal e } \\
\text { prod. animais }\end{array}$ & 1,5 & 0,7 & 0,1 & 0,0 \\
\hline $\begin{array}{l}\text { Produtos } \\
\text { vegetais }\end{array}$ & 2,9 & 1,3 & 0,3 & 0,2 \\
\hline $\begin{array}{l}\text { Produtos } \\
\text { alimentícios }\end{array}$ & 7,5 & 2,9 & 0,5 & 0,3 \\
\hline $\begin{array}{l}\text { Produtos } \\
\text { minerais }\end{array}$ & 3,5 & 8,5 & 0,4 & 0,4 \\
\hline Químico & 11,3 & 11,0 & 10,0 & 13,5 \\
\hline $\begin{array}{l}\text { Plástico/ } \\
\text { borracha }\end{array}$ & 8,3 & 7,7 & 3,2 & 3,4 \\
\hline $\begin{array}{l}\text { Couros e } \\
\text { peles }\end{array}$ & 0,1 & 0,1 & 3,0 & 1,3 \\
\hline Madeira & 5,2 & 3,2 & 1,3 & 0,8 \\
\hline Têxtil & 5,1 & 3,2 & 12,3 & 6,4 \\
\hline Calçados & 0,8 & 1,3 & 8,0 & 2,1 \\
\hline Pedra/vidro & 1,9 & 1,3 & 2,0 & 1,2 \\
\hline Metais & 9,6 & 9,4 & 5,0 & 3,8 \\
\hline $\begin{array}{l}\text { Máquinas/ } \\
\text { elétrico }\end{array}$ & 18,7 & 20,8 & 31,3 & 51,0 \\
\hline Transporte & 21,3 & 26,9 & 3,0 & 6,7 \\
\hline $\begin{array}{l}\begin{array}{l}\text { Produtos } \\
\text { diversos }\end{array} \\
\end{array}$ & 2,2 & 1,8 & 19,7 & 9,0 \\
\hline Total & 100,0 & 100,0 & 100,0 & 100,0 \\
\hline
\end{tabular}

Fonte: Cálculo dos autores com base nos dados da BACI.

2001, apresentou trajetória linearmente crescente, passando de 2.020 para 2.441. Após leve redução em 2002, o número total de produtos exportados pela China para o referido mercado entrou em uma nova trajetória ascendente, quando alcançou 3.179, em 2009. Comparando o ano inicial (1995) com o ano final da análise (2009), é possível verificar que, enquanto 
Tabela 2_Número de produtos exportados pelo Brasil, pela China e simultaneamente por ambos os países para o Mercosul

\begin{tabular}{|c|c|c|c|}
\hline Ano & Brasil & China & Por ambos os países \\
\hline 1995 & 3.668 & 2.020 & 1.756 \\
\hline 1996 & 3.637 & 2.093 & 1.810 \\
\hline 1997 & 3.573 & 2.214 & 1.877 \\
\hline 1998 & 3.545 & 2.301 & 1.966 \\
\hline 1999 & 3.543 & 2.299 & 1.962 \\
\hline 2000 & 3.497 & 2.426 & 2.053 \\
\hline 2001 & 3.509 & 2.441 & 2.031 \\
\hline 2002 & 3.251 & 2.169 & 1.723 \\
\hline 2003 & 3.330 & 2.424 & 1.980 \\
\hline 2004 & 3.398 & 2.691 & 2.224 \\
\hline 2005 & 3.491 & 2.797 & 2.381 \\
\hline 2006 & 3.406 & 3.056 & 2.502 \\
\hline 2007 & 3.403 & 3.086 & 2.598 \\
\hline 2008 & 3.327 & 3.178 & 2.661 \\
\hline 2009 & 3.253 & 3.179 & 2.606 \\
\hline
\end{tabular}

Fonte: Cálculo dos autores com base nos dados da BACI.

a China agregou 1.159 produtos à sua pauta de exportação no Mercosul, o Brasil sofreu redução de 415 produtos.

Os dados reportados na Tabela 2 mostram ainda o número de produtos que são simultaneamente exportados pelo Brasil e pela China para o Mercosul. Percebe-se que os produtos exportados por ambos os países, no período entre 1995 e 2001, apresentou comportamento crescente, passando de 1.756 para 2.031, em que, após sofrer pequena redução em 2002, o número de produtos simultaneamente exportados voltou a crescer, passando, entre os anos 2003 e 2009, de 1.980 para 2.606. Ou seja, os dados informam que, em 2009, em torno de $80,0 \%$ dos produtos exportados pelo Brasil também foram exportados pela China, o que pode ser um in- dício de que a competição entre esses países no Mercosul tem se tornado mais acirrada ao longo dos anos.

A Tabela 3 apresenta o número médio de produtos exportados pelo Brasil, pela China e simultaneamente por ambos os países para o Mercosul, decomposto por setores, nos períodos de 1995/1997 e 2007/2009. Nesse caso, destaca-se que, tanto para o Brasil quanto para a China, a maior parte dos produtos exportados concentra-se nos setores Máquinas/Elétrico, Têxtil e Químico. Um ponto interessante a destacar nesses dados é que, entre os períodos de 1995/1997 e 2007/2009, a China elevou o número de produtos exportados para o Mercosul em todos os setores, ao passo que o Brasil apresentou comportamento inverso, uma vez que reduziu o número de produtos exportados em praticamente todos os setores; a exceção foi o setor de Plástico/Borracha, que teve aumento de dois produtos.

Em consequência disso, no período 2007/2009, percebe-se que, nos setores Máquinas/Elétrico, Produtos Diversos, Têxtil, Calçados e Pedra/Vidro, o número de produtos exportados pela China já é superior ao de produtos exportados pelo Brasil. Convém ainda destacar que, como o aumento da penetração chinesa no Mercosul ocorreu em praticamente todos os setores, os produtos simultaneamente exportados pelo Brasil e pela China para esse bloco econômico também aumentaram em todos os setores, em que, para os setores Máquinas/Elétrico, Químico, Metais e Têxtil, a elevação foi de 156, 154, 134 e 127 produtos, respectivamente.

Em resumo, os dados reportados na presente seção indicam que, entre o período de 1995 e 2009, a China vem aumentando as suas exportações para o Mercosul e que, ademais, esse aumento tem sido acompanhado de uma elevação no número total de produtos comercializados. Os dados sugerem que, com esse aumento do número de produtos exportados, a pauta de exportação da China para o Mercosul tem se tornado mais similar à do Brasil, já que, em 2009, em torno de $80,0 \%$ dos produtos exportados pelo Brasil também o foram 
Tabela 3_Número de produtos exportados pelo Brasil, pela China e simultaneamente por ambos os países para o Mercosul por setores [valores médios para os subperíodos 1995/1997 e 2007/2009]

\begin{tabular}{|c|c|c|c|c|c|c|}
\hline \multirow{2}{*}{ Setor } & \multicolumn{2}{|l|}{ Brasil } & \multicolumn{2}{|l|}{ China } & \multicolumn{2}{|l|}{ Por ambos os países } \\
\hline & $1995 / 1997$ & 2007/2009 & $1995 / 1997$ & 2007/2009 & $1995 / 1997$ & २००७/२००९ \\
\hline Animal e prod. animais & 74 & 58 & 8 & 15 & 3 & 6 \\
\hline Produtos vegetais & 160 & 155 & 40 & 63 & 28 & 45 \\
\hline Produtos alimentícios & 137 & 130 & 21 & 62 & 21 & 58 \\
\hline Produtos minerais & 81 & 78 & 14 & 40 & 11 & 33 \\
\hline Químico & 542 & 506 & 307 & 485 & 236 & 390 \\
\hline Plástico/borracha & 170 & 172 & 79 & 147 & 77 & 141 \\
\hline Couros e peles & 39 & 32 & 25 & 32 & 22 & 26 \\
\hline Madeira & 174 & 145 & 72 & 117 & 66 & 104 \\
\hline Têxtil & 575 & 526 & 422 & 604 & 346 & 472 \\
\hline Calçados & 44 & 38 & 45 & 48 & 38 & 37 \\
\hline Pedra/vidro & 136 & 121 & 76 & 123 & 69 & 101 \\
\hline Metais & 471 & 427 & 213 & 378 & 204 & 339 \\
\hline Máquinas/elétrico & 670 & 618 & 454 & 649 & 427 & 583 \\
\hline Transporte & 91 & 87 & 50 & 76 & 47 & 65 \\
\hline Produtos diversos & 262 & 235 & 284 & 309 & 219 & 223 \\
\hline
\end{tabular}

Fonte: Cálculo dos autores com base nos dados da BACI.

pela China. No entanto, uma análise mais acurada acerca do grau da similaridade das exportações do Brasil e da China para o Mercosul será realizada na próxima seção, mediante a mensuração do índice ISE, de Finger e Kreinin (1979).

\section{2_Mensuração e decomposição do Índice de Similaridade das Exportações (ISE) ${ }^{11}$}

$\mathrm{Na}$ presente seção, aplicar-se-á a estratégia empírica descrita na seção anterior às exportações do Brasil e da China para o Mercosul. Destaca-se que a análise dos dados será dividida em duas etapas. Na primeira etapa (subseção 4.2.1.), a análise será realizada de forma agregada, em que será considerado todo o comércio do Brasil e da China com o Mercosul. Na segunda etapa (subseção 4.2.2.), a análise será desagregada por setores.

\subsection{1_Análise agregada}

A Figura 3 apresenta a evolução do índice de similaridade das exportações (ISE) do Brasil e da China para o Mercosul, no período compreendido entre 1995 e 2009. Nessa figura, é possível notar, claramente, que as exportações do Brasil e da China têm se tornado mais similares ao longo do tempo, tendo em vista que o índice ISE teve comportamento crescente durante o período analisado. Comparando apenas o ano inicial (1995) ao ano final (2009) do período, o referido índice passou de 0,13 para 0,22, o que denota variação de 69,2\%. 
Figura 3_Evolução do Índice de Similaridade das Exportações (ISE) periodo 1995 a 2009

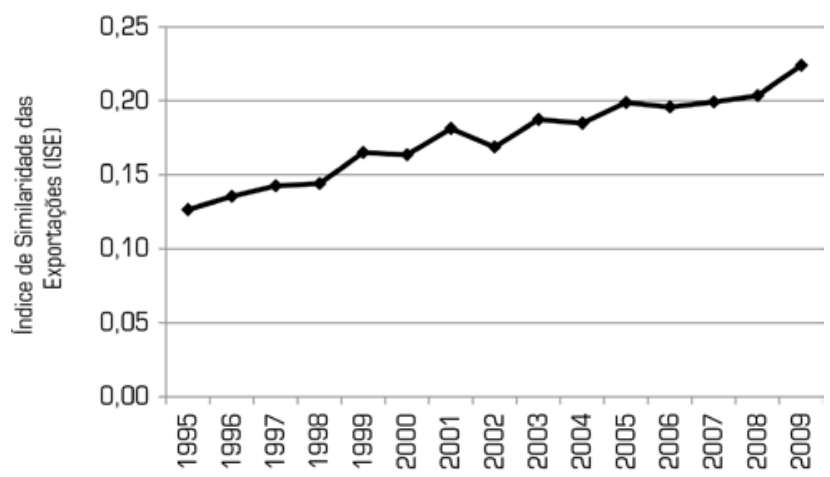

Fonte: Cálculo dos autores com base nos dados da BACI.

Cabe ressaltar que as evidências encontradas no presente trabalho tiveram comportamento muito distinto do verificado no mercado norte-americano, como ressaltado em Filgueiras e Kume (2010). Nesse estudo, os resultados mostraram que a similaridade das exportações do Brasil e da China para o mercado norte-americano aumentou de 0,11 para 0,15, entre os anos 2000 e 2005, mas voltou a reduzir após esse ano, atingindo, em 2008, o valor de 0,10. ${ }^{12}$ Já no presente artigo verificou-se na Figura 3 que a similaridade das exportações do Brasil e da China para o Mercosul apresentou comportamento continuamente crescente; 0 que pode ser um indício de que a competição entre Brasil e China no Mercosul tem se tornado mais acirrada ao longo do tempo.

Por outro lado, argumentou-se anteriormente que a competição entre o Brasil e a China pode ser suavizada caso os produtos comercializados pelos países sejam diferenciados verticalmente, uma vez que, nessa situação, se acredita que os mesmos serão comercializados em distintos segmentos de mercado, como afirma Fontagné et al. (2007). Portanto, desagregou-se o índice ISE, em ISE ${ }^{\mathrm{H}}$ e ISE ${ }^{\mathrm{V}}$, conforme o cri-
Tabela 4_Decomposição do índice ISE em ISE ${ }^{\mathrm{H}}$ e ISE ${ }^{\mathrm{V}}$ (dados em porcentagem)

\begin{tabular}{|c|c|c|}
\hline Ano & ISE $^{H}$ & ISEV $^{2}$ \\
\hline 1995 & 11,2 & 88,8 \\
\hline 1996 & 10,6 & 89,4 \\
\hline 1997 & 13,4 & 86,6 \\
\hline 1998 & 7,5 & 92,5 \\
\hline 1999 & 11,3 & 88,7 \\
\hline 2000 & 25,6 & 74,4 \\
\hline 2001 & 28,2 & 71,8 \\
\hline 2002 & 11,1 & 88,9 \\
\hline 2003 & 26,3 & 73,7 \\
\hline 2004 & 21,5 & 78,5 \\
\hline 2005 & 26,9 & 73,1 \\
\hline 2006 & 26,0 & 74,0 \\
\hline 2007 & 25,6 & 74,4 \\
\hline 2008 & 25,7 & 74,3 \\
\hline 2009 & 23,4 & 76,6 \\
\hline
\end{tabular}

Fonte: Cálculo dos autores com base nos dados da BACI.

tério de similaridade dos produtos. Esses resultados estão reportados na Tabela 4.

Observa-se na Tabela 4 que a similaridade das exportações ocorre majoritariamente em produtos diferenciados verticalmente, isto é, em produtos com distintas qualidades. Nesse caso, a representatividade do índice $\mathrm{ISE}^{\mathrm{V}}$ em relação ao índice ISE ultrapassa, durante todo o período, a magnitude de $70 \%$. Dessa forma, conforme a discussão apresentada nas seções anteriores do presente trabalho, acredita-se que a competição entre os produtos brasileiros e chineses no Mercosul tem sido atenuada, tendo em vista que esses parecem se destinar para diferentes segmentos de mercado.

Considerando que os produtos simultaneamente exportados pelo Brasil e pela China para o Mercosul são diferen- 
Tabela 5_Decomposição do índice ISE em ISE ${ }^{V-\text { Inf. e ISE }}$ ISup. $^{\text {V-Sup }}$ (dados em porcentagem)

\begin{tabular}{|c|c|c|}
\hline Ano & ISE $E^{- \text {-nf. }}$ & ISE ${ }^{\text {V-Sup. }}$ \\
\hline 1995 & 18,6 & 81,4 \\
\hline 1996 & 15,6 & 84,4 \\
\hline 1997 & 13,0 & 87,0 \\
\hline 1998 & 9,3 & 90,7 \\
\hline 1999 & 12,9 & 87,1 \\
\hline 2000 & 11,9 & 88,1 \\
\hline 2001 & 14,8 & 85,2 \\
\hline 2002 & 15,7 & 84,3 \\
\hline 2003 & 21,6 & 78,4 \\
\hline 2004 & 19,4 & 80,6 \\
\hline 2005 & 18,0 & 82,0 \\
\hline 2006 & 11,6 & 88,4 \\
\hline 2007 & 13,4 & 86,6 \\
\hline 2008 & 13,0 & 87,0 \\
\hline 2009 & 9,4 & 90,6 \\
\hline
\end{tabular}

Fonte: Cálculo dos autores com base nos dados da BACI.

ciados verticalmente, ou seja, possuem distintas qualidades, torna-se interessante identificar se a qualidade dos produtos exportados pelo Brasil é superior ou inferior à dos produtos exportados pelo China. Ressalta-se que isso é averiguado nos dados da Tabela 5 .

Conforme os dados reportados na Tabela 5, percebe-se que, quando os produtos simultaneamente exportados pelo Brasil e pela China possuem distintas qualidades, a qualidade dos produtos brasileiros é superior à dos produtos chineses, em que, com exceção do ano de 2003, o ISE ${ }^{\mathrm{V}-\mathrm{Sup} \text {. }}$ representa, pelo menos, $80 \%$ do ISE ${ }^{\mathrm{V}}$. É importante ressaltar que os dados reportados na Tabela 5 estão em consonância com os resultados verificados em Filgueiras e Kume (2010), visto que esses autores também evidenciaram que, no mercado norte-americano, a qualidade dos produtos exportados pelo Brasil é superior à dos produtos exportados pela China.

Conforme o pressuposto principal dos modelos neo-Hecksher-Ohlin (Falvey, 1981; Falvey; Kierkowski, 1987), a qualidade dos produtos exportados está diretamente associada à razão capital/trabalho dos países, em que o país com a maior razão capital/trabalho exportará um produto de qualidade superior a do país com menor razão capital/trabalho. Portanto, acredita-se que a maior qualidade do produto brasileiro em relação à do produto chinês se deve a maior razão capital-trabalho do Brasil perante a China. ${ }^{13}$ Destaca-se que os resultados aqui analisados estão em consonâncias com outros estudos encontrados na literatura, os quais também observam a existência de uma especialização intraproduto no comércio internacional (Hummels; Klenow, 2005; Schott, 2006; entre outros).

Em resumo, os dados reportados na presente subseção revelam que a similaridade das exportações do Brasil e da China para o Mercosul vem aumentando ao longo do tempo, sugerindo que a competição entre os países no referido mercado esteja ficando mais acirrada ao longo do tempo. No entanto, conforme o critério de similaridade dos produtos, evidenciou-se que a competição entre os produtos brasileiros e chineses é suavizada, tendo em vista que a maior parte dos produtos comercializados é diferenciada verticalmente. Ademais, observou-se que a qualidade dos produtos brasileiros é superior à dos produtos chineses.

\subsection{2_Análise setorial}

Na presente subseção, realiza-se uma análise da similaridade das exportações do Brasil e da China para o Mercosul por setores. Neste caso, convém salientar que, para evitar grande dispersão nas informações, os dados serão reportados em valo- 
Tabela 6_Índice de Similaridade das Exportações (ISE) por setores industriais [valores médios por subperíodos]

\begin{tabular}{l|r|r|r}
\hline Setor & $1995 / 1997$ & $2001 / 2003$ & $2007 / 2009$ \\
\hline Animal e prod. animais & 0,01 & 0,03 & 0,01 \\
\hline Produtos vegetais & 0,02 & 0,04 & 0,04 \\
\hline Produtos alimentícios & 0,20 & 0,09 & 0,22 \\
\hline Produtos minerais & 0,03 & 0,08 & 0,04 \\
\hline Químico & 0,17 & 0,24 & 0,19 \\
\hline Plástico/borracha & 0,21 & 0,27 & 0,42 \\
\hline Couros e peles & 0,25 & 0,07 & 0,11 \\
\hline Madeira & 0,08 & 0,11 & 0,22 \\
\hline Têxtil & 0,22 & 0,22 & 0,30 \\
\hline Calçados & 0,53 & 0,49 & 0,70 \\
\hline Pedra/vidro & 0,16 & 0,25 & 0,35 \\
\hline Metais & 0,15 & 0,19 & 0,28 \\
\hline Máquinas/elétrico & 0,18 & 0,26 & 0,27 \\
\hline Transporte & 0,14 & 0,08 & 0,20 \\
\hline Produtos diversos & 0,19 & $\ldots, 25$ & 0,26 \\
\hline Fon & $\ldots . .$. &...
\end{tabular}

Fonte: Cálculo dos autores com base nos dados da BACI.

res médios para os seguintes subperíodos: 1995/1997, 2001/2003, 2007/2009. Esses dados estão apresentados na Tabela 6.

Nota-se, na Tabela 6, que o maior índice de similaridade das exportações ocorre no setor de Calçados, o qual, após sofrer pequena queda, de 0,53 para 0,49, entre os períodos de 1995/1997 e 2001/2003, atinge a magnitude de 0,70, no período de 2007/2009. ${ }^{14}$ Além do setor de Calçados, os de Plástico/ Borracha e de Pedra/Vidro são outros que merecem destaque. Em 1995/1997, o setor de Plástico/Borracha figurava apenas na quarta posição no tocante ao índice ISE, com 0,21, permanecendo atrás dos setores de Couros e Peles $(0,25)$ e Têxtil $(0,22)$. Mas, ao longo dos períodos, observou-se elevação contínua do índice ISE, atingindo 0,27 e 0,42, nos períodos de 2001/2003 e 2007/2009, respectivamente.Já o setor de Pedra/
Vidro, no primeiro período (1995/1997), figura apenas na nona colocação no que tange ao índice ISE (com 0,16), mas, nos períodos seguintes, 2001/2003 e 2007/2009, esse setor aparece, respectivamente, na quinta e terceira posição, com índices iguais a 0,25 e 0,35 , respectivamente.

Ainda com relação aos dados da Tabela 6, nota-se que o índice ISE tanto nos setores que produzem bens primários (Animal e prod. animais e Produtos vegetais) quanto nos setores que são intensivos em recursos naturais (Prod. minerais) é muito baixo; isso ocorre porque a pauta de exportação do Brasil e da China para o Mercosul concentra-se majoritariamente em produtos manufaturados, como fora observado nos dados reportados na Tabela 1.

Adotando o mesmo procedimento da subseção anterior, desagregou-se o índice ISE, em ISE ${ }^{\mathrm{H}}$ e ISE ${ }^{\mathrm{V}}$, para os 15 setores. Esses resultados estão reportados na Tabela 7, em porcentagens médias para os subperíodos: 1995/1997, 2001/2003 e 2007/2009. Chama a atenção o fato de que, para todos os setores analisados, o índice ISE ocorre majoritariamente em produtos verticalmente diferenciados, tendo em vista que o ISE ${ }^{\mathrm{V}}$ é superior ao $\mathrm{ISE}^{\mathrm{H}}$. Mas destaca-se que, para alguns setores, Produtos Vegetais, Madeira e Pedra/Vidro, observa-se crescimento do ISE ${ }^{\mathrm{H}}$, sobretudo no último subperíodo (2007/2009). Isso sugere que nesses setores a qualidade dos produtos brasileiros e chineses tornou-se mais similar ao longo dos anos.

Os dados destacados na Tabela 8 mostram se a qualidade do produto brasileiro é superior ou inferior à do produto chinês, quando esses são verticalmente diferenciados. Como se pode observar, na maioria dos setores, a qualidade dos produtos exportados pelo Brasil é superior à dos produtos exportados pela China, pois o ISE $\mathrm{V}^{\mathrm{V}-\mathrm{Sup} \text { é maior do que o ISE }} \mathrm{I}^{\mathrm{V} \text {-Inf. }}$. Destaca-se que esses resultados são estáveis ao longo do tempo, uma vez que não se verificam mudanças abruptas nas porcentagens entre os subperíodos analisados. 
Tabela 7_Decomposição do índice ISE em ISE e ISEV por setores (valores médios percentuais por subperiodos)

\begin{tabular}{|c|c|c|c|c|c|c|}
\hline \multirow{2}{*}{ Setor } & \multicolumn{2}{|c|}{ 1995/1997 } & \multicolumn{2}{|c|}{ २००१/२००૩ } & \multicolumn{2}{|c|}{ २००7/२००९ } \\
\hline & ISE $^{\mathrm{H}}$ & ISEV $^{2}$ & ISEH $^{H}$ & ISEV $^{2}$ & ISEH $^{H}$ & ISEV $^{2}$ \\
\hline Animal e prod. animais & 0,0 & 100,0 & 0,1 & 99,9 & 35,6 & 64,4 \\
\hline Produtos vegetais & 5,8 & 94,2 & 10,8 & 89,2 & 42,5 & 57,5 \\
\hline Produtos alimentícios & 16,8 & 83,2 & 31,1 & 68,9 & 21,0 & 79,0 \\
\hline Produtos minerais & 15,5 & 84,5 & 21,1 & 78,9 & 19,2 & 80,8 \\
\hline Químico & 17,9 & 82,1 & 23,5 & 76,5 & 36,6 & 63,4 \\
\hline Plástico/borracha & 28,0 & 72,0 & 17,2 & 82,8 & 31,7 & 68,3 \\
\hline Couros e peles & 1,3 & 98,7 & 6,2 & 93,8 & 26,5 & 73,5 \\
\hline Madeira & 8,8 & 71,2 & 23,1 & 76,9 & 48,9 & 51,1 \\
\hline Têxtil & 9,6 & 90,4 & 23,8 & 76,2 & २०,२ & 79,8 \\
\hline Calçados & 15,6 & 84,4 & 25,6 & 74,4 & 9,1 & 90,9 \\
\hline Pedra/vidro & 23,9 & 76,1 & 27,9 & 72,1 & 43,3 & 56,7 \\
\hline Metais & 9,7 & 90,3 & 22,0 & 78,0 & 30,5 & 69,5 \\
\hline Máquinas/elétrico & 8,0 & 92,0 & 17,7 & 82,3 & 27,2 & 72,8 \\
\hline Transporte & 6,5 & 93,5 & 36,6 & 63,4 & 13,8 & 86,2 \\
\hline Produtos diversos & 8,7 & 91,3 & 16,8 & 83,2 & 10,7 & 89,3 \\
\hline
\end{tabular}

Fonte: Cálculo dos autores com base nos dados da BACI.

Contudo, fogem à regra os setores Animal e produtos animais, Produtos vegetais, Produtos alimentícios e Produtos minerais, visto que nesses o ISE $\mathrm{E}^{\mathrm{V}-\mathrm{Inf} .}$ supera o ISE $\mathrm{I}^{\mathrm{V} \text {-Sup. }}$. Especificamente no caso do setor de Produtos minerais, nota-se alteração no padrão de diferenciação dos produtos entre os subperíodos, pois, em 1995/1997 e em 2007/2009, o ISE ${ }^{\mathrm{V}-\mathrm{Inf}}$. é maior do que o ISE ${ }^{\mathrm{V}-S u p}$, e o contrário ocorre em 2001/2003. Cabe aqui ressaltar que, como o índice de similaridade das exportações (ISE) nesse setor é muito baixo (como reportado na Tabela 6), a magnitude setorial pode ser altamente influenciada pelo comportamento de um ou outro produto, o que torna os resultados relativamente mais instáveis.
Tabela 8_Decomposição do índice ISE ${ }^{\mathrm{V}}$ em ISE ${ }^{\mathrm{V}-\mathrm{Inf}}$ e ISE IS-Sup. $^{\mathrm{V}}$ [porcentagens médias por subperíodos]

\begin{tabular}{|c|c|c|c|c|c|c|}
\hline Setor & $\begin{array}{l}1995 / \\
\text { ISEV-Inf. }^{-}\end{array}$ & 1997 & $\begin{array}{l}2001 / \\
\text { ISEV-Inf. }\end{array}$ & $\begin{array}{l}2003 \\
\text { ISEV-Sup. }\end{array}$ & $\begin{array}{l}\text { २००७/ } \\
\text { ISEV-Inf. }\end{array}$ & |२००९ \\
\hline Animal e prod. animais & 96,6 & 3,4 & 97,1 & 2,9 & 84,6 & 15,4 \\
\hline Produtos vegetais & 72,1 & 27,9 & 53,8 & 46,2 & 76,4 & 23,6 \\
\hline Produtos alimentícios & 22,9 & 77,1 & 64,7 & 35,3 & 63,7 & 36,3 \\
\hline Produtos minerais & 67,2 & 32,8 & 15,1 & 84,9 & 84,8 & 15,2 \\
\hline Químico & 35,3 & 64,7 & 7,7 & 92,3 & 33,9 & 66,1 \\
\hline Plástico/borracha & 19,2 & 80,8 & 5,9 & 94,1 & 3,8 & 96,2 \\
\hline Couros e peles & 16,9 & 83,1 & 4,1 & 95,9 & 4,8 & 95,2 \\
\hline Madeira & 41,1 & 58,9 & 44,1 & 55,9 & 48,4 & 51,6 \\
\hline Têxtil & 7,3 & 92,7 & 11,0 & 89,0 & 6,9 & 93,1 \\
\hline Calçados & 2,1 & 97,9 & 38,5 & 61,5 & 0,7 & 99,3 \\
\hline Pedra/vidro & 44,4 & 55,6 & 30,6 & 69,4 & 15,4 & 84,6 \\
\hline Metais & 9,5 & 90,5 & 10,8 & 89,2 & 13,6 & 86,4 \\
\hline Máquinas/elétrico & 10,1 & 89,9 & 20,2 & 79,8 & 12,0 & 88,0 \\
\hline Transporte & 4,7 & 95,3 & 15,5 & 84,5 & 5,8 & 94,2 \\
\hline Produtos diversos & 13,0 & 87,0 & 17,6 & 82,4 & 13,1 & 86,9 \\
\hline
\end{tabular}

Fonte: Cálculo dos autores com base nos dados da BACI.

\section{5_Considerações finais}

O crescimento do comércio internacional da China observado ao longo das últimas décadas pode comprometer a inserção internacional do Brasil, já que, se por um lado a China representa um grande mercado às exportações do país, por outro, as exportações oriundas da China podem ser uma ameaça às exportações brasileiras em outros mercados, caso as exportações de ambos os países se tornem mais similares ao longo do tempo. Contudo, conforme Fontagné et al. (2007), a competição entre os países pode ser atenuada, caso os produtos por eles exportados sejam verticalmente diferenciados. 
Inserindo-se nesse contexto, o presente artigo teve como objetivo principal analisar a competitividade das exportações do Brasil e da China para o Mercosul, durante o período compreendido entre 1995 e 2009. Para tanto, primeiramente se mensurou a similaridade das pautas de exportações dos referidos países para o Mercosul por meio do índice de Finger e Kreinin (1979) para, em seguida, desagregá-lo com base no critério de similaridade dos produtos, em que foi possível identificar se a qualidade dos produtos brasileiros é superior ou inferior à dos produtos chineses.

Utilizando os dados de comércio desagregados ao nível de seis dígitos do Sistema Harmonizado, os resultados obtidos no presente trabalho sugerem que a similaridade das exportações do Brasil e da China para tal bloco econômico vem aumentando ao longo do tempo, passando de 0,11 (em 1995) para 0,22 (em 2009), o que pode ser um indício de que a competição entre os países tem se tornado mais acirrada.

Todavia, por meio da decomposição do índice de Finger e Kreinin (1979), verificou-se que a similaridade das exportações ocorre, majoritariamente, em produtos verticalmente diferenciados, em que a qualidade do produto exportado pelo Brasil é superior à do produto exportado pela China. Isso confirma os resultados sugeridos pelos novos modelos teóricos de comércio adotados neste estudo, como os modelos do tipo "Falvey", os quais sugerem que os países com maior abundância relativa de capital produzirão bens com qualidade superior aos produzidos por países com maior abundância relativa de mão de obra.

Ou seja, por mais que a China esteja ganhando espaço no Mercosul, o Brasil também aumentou sua participação, elevando a proporção principalmente de produtos com maior valor agregado. Neste sentido, como diferentes autores defendem a estratégia de agregar valor às vendas externas para que o país não fique dependente dos preços de commodities, os quais historicamente são muito voláteis, apostando em setores com maior desenvolvimento tecnológico e empregos de melhor qualidade, pode-se concluir que os resultados obtidos sinalizam que o Brasil, pelo menos no mercado do Mercosul, está tentando fazer essa agregação de valor, e a inserção da China nesse mercado não necessariamente está competindo com o Brasil.

\section{Notas}

${ }^{1} \mathrm{O}$ índice de Finger e Kreinin varia no intervalo compreendido entre 0 e 1. Mais detalhes sobre esse, ver seção 3 do presente trabalho.

${ }^{2}$ A escolha do Mercosul se deu pelo fato de esse mercado ser um importante destino dos produtos manufaturados brasileiros (Hıratuka; Cunha, 2011). Ademais, considerou-se como Mercosul os mercados da Argentina, do Paraguai e do Uruguai.

${ }^{3}$ Este pressuposto evita o problema de indeterminação do padrão de comércio o qual ocorre quando se tem mais fatores do que bens finais se os preços dos fatores são equalizados (Bhagwati, 1972).

${ }^{4}$ Paillacar e Zignago (2007) também identificam que as exportações chinesas estão concentradas em produtos de baixa qualidade.

${ }^{5}$ Destaca-se que a aplicação do critério de similaridade dos produtos no índice de Finger e Kreinin (1979) constitui uma inovação do presente trabalho, já que os trabalhos encontrados na literatura (Abd-El-Rahman, 1991; Greenaway et al., 1994; Fontagné;
Freudenberg, 1997; Durkın; Krygier, 2000; Nielsen; Lüthje, 2002; Crespo; Fontoura, 2004; Jensen; Lüthje, 2009) empregam o critério de similaridade dos produtos para a desagregação do índice de Grubel e Lloyd (1975).

${ }^{6}$ Seguindo a literatura padrão (Greenaway et al., 1994; Fontagné; Freudenbrg, 1997; Schott, 2004; Crespo; Fountoura, 2004; Fontagné et al., 2007; Jensen; Lüthje, 2009; Hıratuka; Cunha, 2011), o valor unitário do produto será calculado por meio da divisão do valor monetário $(\mathrm{V})$ pela quantidade comercializada (Q), isto é: $\mathrm{VU}=\mathrm{V} / \mathrm{Q}$.

${ }^{7}$ Destaca-se que Abd-el-Rahman (1991), Fontagné et al. (1997) e Jensen e Lüthje (2009) utilizam um fator de dispersão ( $\alpha$ ) igual a 15\%. Conforme Greenaway et al. (1995), a adoção de um fator de dispersão igual a 15\% resultará em um intervalo de dispersão igual a $30 \%$, o qual pode ser considerado muito estreito, se prevalece no mercado a informação imperfeita. Desse modo, os autores advogam a utilização de um fator de dispersão igual a $25 \%$, que fornece 
um intervalo de dispersão igual a $50 \%$; com a respectiva margem, espera-se abranger as falhas de informação decorrentes do tamanho e da diversidade do país (Zhang et al. 2005). Cabe destacar que Greenaway et al. (1995),

Durkin e Krygier (2000), Crespo e Fontoura (2004) e Jensen e Lüthje (2009) não encontram diferenças estatisticamente significativas entre os fatores de dispersão de $15 \%$ e de $25 \%$. No entanto, apesar de todo o cuidado na escolha do fator de dispersão, a sua definição ainda possui natureza arbitrária.

Para discussão mais detalhada acerca desse tema, ver Davis e Weinstein (2001).

${ }^{8}$ Stiglitz (1987) descreve diversos modelos que demonstram a relação entre qualidade e preço baseados em efeitos de incentivo e seleção.

${ }^{9}$ Destaca-se que o nível de desagregação usado no presente trabalho está em consonância com outros trabalhos encontrados na literatura. Por exemplo, Paillacar e Zignago (2007) e Hiratuka e Cunha (2011) também utilizam os dados desagregados a seis dígitos do Sistema Harmonizado para analisar a qualidade relativa dos produtos comercializados pelos países.

${ }^{10} \mathrm{Um}$ fato que contribuiu para a maior inserção da China no Mercosul foi a entrada desse país na Organização Mundial do Comércio (OMC), em 2001.

${ }^{11}$ Cabe aqui ressaltar que, para a mensuração e a decomposição da similaridade das exportações do Brasil e da China para o Mercosul, foram utilizadas 192.520 observações, das quais 2.668 (ou $1,38 \%$ ) foram descartadas, por não reportarem a quantidade comercializada.

${ }^{12}$ Destaca-se que os dados utilizados por Filgueiras e Kume (2010) para o cômputo da similaridade das exportações do Brasil e da China para o mercado norte-americano são mais desagregados dos que foram utilizados no presente trabalho, já que, enquanto esses autores utilizaram os dados desagregados ao nível de 10 dígitos, no presente trabalho os dados estão desagregados a seis dígitos. Sendo assim, como ressaltamos na subseção 3.2, dados mais desagregados tendem a fornecer menores valores do índice ISE do que dados mais agregados.

${ }^{13}$ Conforme o Banco Mundial (2009 apud Filgueira; Kume, 2010) a renda per capita, mensurada pela paridade do poder de compra, do Brasil, em 2008, foi de US\$ 10.070, ao passo que a da China, nesse mesmo ano, foi de US\$ 6.020 . Ressalta-se que a lógica para a utilização da renda per capita como proxy da razão capital/ trabalho é a seguinte: considere que $\mathrm{Y}=\mathrm{F}(\mathrm{K}, \mathrm{L})$, em que $\mathrm{Y}$ denota o PIB, K é a quantidade de capital físico, L denota o número de trabalhadores e F(.) é uma função homogênea de grau 1. Dessa forma, dividindo ambos os lados da função por L, temos: $y=f(k)$; onde $\mathrm{y}=\mathrm{Y} / \mathrm{L}$ e $\mathrm{k}=\mathrm{K} / \mathrm{L}$.

\author{
${ }^{14}$ Provavelmente essas alterações \\ neste setor foram causadas pela \\ política cambial adotada no Brasil, \\ em cada período.
}


ABD-EL-RAHMAN, K. 'Firms' competitive and national comparative advantages as joint determinants of trade composition. Weltwirtschaftliches Archiv, v. 127, n. 1, p. 83-97, 1991.

BALASSA, B. Trade liberalization among industrial countries: Objectives and alternatives. McGraw-Hill, New York, 1966.

BALDWIN, R. The Euro's Trade Effect. European Central Bank, working paper n ${ }^{\circ}$ 594, 2006.

BANCO MUNDIAL. Key development data \& statistics. 2009. Disponível em: $<\mathrm{http}: / /$ web.worldbank.org/ WBSITE/EXTErNAL/ DATASTATISTICS $>$. Acesso em: 18/10/2011.

BHAGWATI, J. The HeckscherOhlin theorem in the multicommodity case. Journal of Political Economy, vol. 80, p. 1052-1055, 1972.

CAETANO, J.; GALLEGO, A. In search for the determinants of intra-industry trade within an enlarged Europe. South-Eastern Europe Journal of Economics, vol. 2, p. 163-183, 2007.

CHURCH, J.; WARE, R. Industrial organization: A strategic approach. New York: McGraw-Hill, 2000.
CRESPO, N.; FONTOURA, P. Intra-industry trade by types: What can we learn from Portuguese data?. Review of World Economic, 140(I), p. 52-79, 2004.

DAVIS, D. R.; WEINSTEIN, D. E. What role for empirics in international trade? National Bureau of Economic Research (NBER), working paper 8.543, 2001.

DEARDORFF, A. Weak links in the chain of comparative advantage. Journal of International Economics, vol. 9, p. 198-209, 1979.

DURKIN, J. T.; KRYGIER, M. Difference in GDP per capita and the share of intraindustry trade: The role of vertically differentiated trade. Review of International Economics, vol. 4, n. 8, p. $760-774,2000$.

FALVEY, R. Commercial policy and intra-industry trade. Journal of International Economics, vol. 11, p. 495-511, 1981.

FALVEY, R.; KIERZKOWSKI, H. Product quality, intra-industry trade and (im)perfect competition. In: KIERZKOWSKI, Henryk (Ed.). Protection and competition in International Trade: Essays in Honour of W.M. Corden, Oxford, p. 143-161, 1987.
FARUQ, H. Impact of technology and physical capital on export quality. The Journal of Developing Areas, vol. 44, n. 1, p. 167-185, 2010.

FILGUEIRAS, M.; KUME, H. A competitividade do Brasile da China no mercado norte-americano: 20002008. Instituto de Pesquisa Econômica Aplicada (IPEA), texto para discussão $n^{\circ} 1.501,2010$.

FINGER, J. M.; KREININ, M. E. A measure of "Export Similarity" and its possible uses. Economic Journal, vol. 89, Dec. 1979.

FLAM, H.; HELPMAN, E. Vertical product differentiation and north-south trade. American Economic Review, vol. 77, n. 5, p. $810-822,1987$.

\section{FONTAGNÉ, L.; FREUDENBERG,} M. Intra-industry trade:

Methodological issues reconsidered. Centre d'Etudes Prospectives et d'Informations Internationales (CEPII), working paper nº 1997-01, 1997.

FONTAGNÉ, L.; GAULIER, G.; ZIGNAGO, S. Specialization across varities within products and NorthSouth competition. Centre d'Etudes Prospectives et d'Informations Internationales (CEPII), working paper no 2007-06, 2007.
GAULIER, G.; ZIGNAGO, S. BACI: International database at the product-level. Centre d'Etudes Prospectives et d'Informations Internationales (CEPII), working paper $\mathrm{n}^{\circ} 2010-23,2010$.

GREENAWAY, D.; HINE, R.; MILNER, C. Country specific factors and the pattern of horizontal and vertical intraIndustry trade in the UK. Weltwirtschaftliches Archiv, v. 130, n. 1, p. 77-100, 1994.

GREENAWAY, D.; HINE, R.; MILNER, C. Vertical and horizontal intra-industry trade: A cross-industry analysis for the United Kingdom. Economic Journal, vol. 105, p. 1505-1518, 1995.

GREENAWAY, D.; MILNER, C. The economics of intra-Industry trade. Oxford Press, 1986.

GROSSMAN, G. M.; HELPMAN, E. Quality ladders and product cycles. Quarterly Journal of Economics, vol. 106, n. 2, p. 557-586, 1991.

GRUBEL, H. G. Intra-industry trade specialization and the pattern of trade. Canadian Journal of Economics and Political Science, vol. 33, n. 3, p. 374-388, 1967 .

GRUBEL, H. G.; LOYD, P. J. Intraindustry trade: The theory and measumement of international trade in differentiated products. London, MacMillian, 1975. 
HELPMAN, E.; KRUGMAN, P.

R. Market structure and foreign trade: Increasing returns, imperfect competition and the international economy. MIT Press, Cambridge, MA, 1985.

HIRATUKA, C.; CUNHA, S. Qualidade e diferenciação das exportações brasileiras e chinesas: Evolução recente no mercado mundial e na ALADI. Instituto de Pesquisa Econômica Aplicada (IPEA), texto para discussão $\mathrm{n}^{\mathrm{o}} 1.622,2011$.

HUMMELS, D.; KLENOW, P. J. The variety and quality of a nation's exports. The American Economic Review, vol. 95, n. 3, p. 704-723, 2005.

IPEA. As relações bilaterais Brasil China: A ascensão da China no sistema mundial e os desafios para o Brasil. Comunicado IPEA, no 85, 2011.

JENSEN, L.; LÜTHJE, T. Driving forces of vertical intra-industry trade in Europe 1996-2005. Review of World Economics, vol. 145, p. 469-488, 2009.

JONES, R. The small country in a many-commodity world. Australian Economic Papers, vol. 13, p. 225-236, 1974.

KANG, M.; LEE, J. D. Vertical intra-industry trade and product quality: The case of South Korea, 1996-2003. Economics and Business Letters, vol. 1(3), p. 37-47, 2012.

KRISHNA, P.; MALONEY, W. F. Export quality dynamics. The World Bank, working paper $n^{\circ}$ 5701, 2011.
KRUGMAN, P. Increasing returns, monopolistic competition and international trade. Journal of International Economics, vol. 9, n. 4,

p. $469-479,1979$.

KRUGMAN, P. Scale economies, product differentiation, and the pattern of trade. American Economic Review, vol. 70, n. 5 , p. $950-959,1980$

KRUGMAN, P. Intraindustry specialization and gains from trade. The Journal of Political Economy, vol. 89, n. 5, p. $959-973,1981$.

NIELSEN, J. U. M.; LÜTHJE,

T. Tests of the empirical classification of horizontal and vertical intra-industry trade. Weltwirtschaftliches Archiv/Review of World Economics, vol. 138, n. 4 , p. 587-604, 2002

PAILLACAR, R.; ZIGNAGO, S. Product differentiation and performance of Latin American exports. Centre d'Etudes Prospectives et d'Informations Internationales (CEPII), 2007.

REGANATI, F; PITTIGLIO, R.

Vertical intra-industry trade:

Patterns and determinants in the Italian case. Quaderni DSEMS, nº 06, Dipartimento di Scienze Economiche, Matematiche e Statistiche, Universita' di Foggia, 2005.

RODRIK, D. What's so special about China's exports? John Kennedy School of Government, Harvard University, working paper 06-001, 2006.
SCHOTT, P. Across-product versus within-product specialization in international trade. The Quarterly Journal of Economics, MIT Press, vol. 119, n. 2, p. 646-677, May 2004.

SCHOTT, P. The relative sophistication of Chinese exports, NBER working paper 12173, 2006.

STIGLITZ, J. E. The causes and consequences of the dependence of quality on price. Journal of Economic Literature, vol. 25 , p. $1-48,1987$

ZHANG, J.; WITTELOOSTUIJN A.; ZHOU, C. Chinese bilateral intra-industry trade: A panel data study for 50 countries in the 1992-2001 period. Review of World Economics, vol. 141, n. 3, p. 510-540, 2005. 
